\title{
Komunikasi Persuasif dan Penerapannya di Daya Tarik Wisata Tebing Keraton
}

\author{
Evi Novianti ${ }^{1,2}$, Cipta Endyana ${ }^{2}$, Elnovani Lusiana ${ }^{3}$, Shandra Rama Panji Wulung ${ }^{4}$, \\ Rahmatika Desiana $^{2}$
}

\author{
${ }^{1}$ Fakultas Ilmu Komunikasi, Universitas Padjadjaran, J1. Raya Bandung Sumedang KM.21, Sumedang \\ ${ }^{2}$ Magister Pariwisata Berkelanjutan, Sekolah Pascasarjana Universitas Padjadjaran, Jl. Dipatiukur No.35 \\ Bandung \\ ${ }^{3}$ Sekolah Pascasarjana Universitas Padjadjaran, Jl. Dipatiukur No.35 Bandung \\ ${ }^{4}$ Pendidikan Pariwisata, Universitas Pendidikan Indonesia, Jl. Dr. Setiabudhi No. 229 Bandung \\ Email: ${ }^{1}$ evi.novianti@unpad.ac.id, ${ }^{2}$ cipta.endyana@unpad.ac.id, ${ }^{3}$ elnovani.lusiana@unpad.ac.id, \\ 4wulung@upi.edu
}

\begin{abstract}
ABSTRAK
Kawasan pariwisata berbasis alam rentan terhadap terjadinya bencana. Tantangan utama untuk menjaga dampak negatif akibat kegiatan wisata yaitu mengajak wisatawan untuk menjaga dan memelihara lingkungan alam melalui media komunikasi yang efektif dan efisien. Penelitian ini bertujuan untuk mengidentifikasi potensi pariwisata di Kampung Ciharegem dan mengidentifikasi media komunikasi persuasif yang ada di Tebing Keraton, Kampung Ciharagem. Penelitian ini menggunakan metode kualitatif teknik perolehan data primer melalui wawancara dan obeservasi lapangan. Sementara data sekunder didapatkan melalui studi pustaka dan dokumen kebijakan terkait. Analisis isi dan deskriptif. Ruang lingkup wilayah penelitian ini meliputi Kampung Ciharegem yang terletak di Desa Ciburial, Kecamatan Cimenyan, Kabupaten Bandung. Hasil penelitian menunjukan bahwa media komunikasi persuasif dapat berkontribusi dalam merancang strategi komunikasi yang efektif bagi destinasi pariwisata yang berada di kawasan lindung. Terdapat dua media komunikasi persuasif utama yang terletak di Kampung Ciharegem, yaitu media fisik berupa spanduk, papan informasi, dan papan petunjuk arah, serta media daring melalui situs web dan media sosial. Pembaharuan konten media daring secara berkala dapat mambantu dan mengedukasi wisatawan yang akan berkunjung ke Tebing Keraton di Kampung Ciharegem
\end{abstract}

Kata kunci; Komunikasi persuasif, Pariwisata Berkelanjutan, Tebing Keraton

\section{Persuasive Communication and Its Application in the Keraton Cliff Tourism Attractions}

\begin{abstract}
Nature-based tourism areas are prone to disasters. The main challenge in preventing the negative impact of tourism activities is inviting tourists to protect and preserve the natural environment through effective and efficient communication media. This study aims to identify tourism potential in Ciharegem Village and identify persuasive communication in Tebing Keraton, Ciharagem Village. This study uses qualitative methods of primary data collection techniques through interviews and field observations. Meanwhile, secondary data is obtained through literature study and related policy documents. Content and descriptive analysis. The scope of this research area includes Ciharegem Village, which is located in Ciburial Village, Cimenyan District, Bandung Regency. The results showed that persuasive communication media can contribute to designing effective communication strategies for tourism destinations that are in protected areas. There are two main persuasive communication media located in Ciharegem Village, namely physical media in the form of banners, information boards, and directions, as well as online media through websites and social media. Regular updates of online media content can help and educate tourists who will visit the Tebing Keraton in Ciharegem Village.
\end{abstract}

Key words; Persuasive communication, Sustainable tourism, Tebing Keraton

\section{PENDAHULUAN}

Tantangan terbesar dalam kepariwisataan adalah mengajak wisatawan untuk tetap menjaga lingkungan dan meminimalisasi dampak negatif, tertutama pada kawasan pariwisata berbasis alam (Brown et al., 2010). Beberapa penelitian terdahulu menunjukkan bahwa semua jenis kegiatan wisata dapat menyebabkan degradasi lingkungan pada tingkat penggunaan rendah (Hammitt \& Cole, 1998). Perilaku dan tingkat kepadatan wisatawan dapat memengaruhi kualitas pengalaman dalam berwisata (Manning, 2007). Pariwisata sangat bergantung pada sumber daya alam, tanpa intervensi dan konsumsi sumber daya yang berlebihan dapat menjadikan kegiatan pariwisata berkelanjutan (Gössling \& Peeters, 2015).

Upaya mengurangi dampak kegiatan wisata di lingkungan alam melalui teknologi berhasil berkontribusi pada penhematan, tetapi tidak cukup untuk mengurangi dalam jangka waktu yang cukuplama (Melissen et al., 2016). Hal tersebut dikarenakan oleh konsumsi yang 
tinggi pada sumber daya di kawasan pariwisata untuk fasilitas bagi wisatawan (Hawkins \& Vorster, 2014). Meskipun demikian, terdapat beberapa penelitian terdahulu yang mengkaji akan efektifitas upaya komunikasi dalam mengubah permintaan pariwisata dan perilaku wisatawan untuk memicu perkembangan pariwisata berkelanjutan (Luchs et al., 2010).

Komunikasi persuasif, meliputi komponen verbal, non-verbal, dan citra (Gass \& Seiter, 2015; O'Keefe, 2002), lebih canggih dan komprehensif dibanding dengan pendekatan periklanan yang asinkron (satu arah). Komunikasi persuasif melibatkan proses simbolis di mana komunikator berusaha meyakinkan orang lain untuk mengubah sikap atau perilaku mereka mengenai suatu masalah melalui transmisi pesan dalam suasana pilihan bebas (Perloff, 1993). Persuasi dapat memengaruhi kondisi mental seseorang melalui langkah-langkah yang berupaya mengubah sikap, yang dapat mengarah pada perubahan perilaku (O'Keefe, 2002). Persuasi berbeda dari mendapatkan kepatuhan dalam yang terakhir berfokus pada perubahan perilaku tanpa harus mengubah sikap (Gass \& Seiter, 2015).

Komunikasi persuasif melibatkan banyak interaksi dalam dialog, di mana persepsi kepercayaan dan kredibilitas komunikator dapat memengaruhi keberhasilan teknik pengaruh atau kepatuhan (Teven \& McCroskey, 1999). Perbedaan suasana hati dan usia juga dapat mempengaruhi persuasi karena perbedaan nilai atau relevansi topik, komunikator yang berhasil memodifikasi pendekatan mereka agar sesuai dengan audiens (Curtin, 2010). Faktor yang menentukan adalah persuasif dari konteks komunikasi (Warren et al., 2017). Situasi sosial termasuk isyarat halus yang ditemukan dalam pertemuan tatap muka dan hal itu mungkin juga sensitif terhadap pesan langsung dan tidak langsung, tergantung pada sosial dan budayanya (Wiseman et al., 1995)

Keberhasilan komunikasi sangat bergantung pada pesan yang disampaikan kepada audiens. Pesan adalah segala sesuatu yang disampaikan oleh seseorang dalam bentuk simbol yang dipersepsi dan diterima oleh khalayak dalam serangkaian makna (Bungin, 2015). Dalam hal ini sebagus apapun ide kalau tidak disusun menururt struktur bahasa yang benar maka ide tersebut tidak akan bisa dipahami oleh audiens kita. Untuk itu dibutuhkan teknik penyusunan pesan, yaitu one-side issue dan two-side issue. One-side issue, yaitu teknik penyampaian pesan yang menonjolkan sisi kebaikan atau keburukan sesuatu. Artinya seorang komunikator dalam menyampaikan pesan harus memberi tekanan apakah kebaikannya atau sebaliknya. Teknik penyampaian ini cocok digunakan mereka yang kurang berpendidikan, sehingga tidak mempunyai alternatif pilihan. Sementara, two-side issue, teknik penyampaian pesan di mana komunikator selain mengemukan hal yang baik-baik juga menyampaikan hal yang kurang baik. Komunikator memberi kesempatan kepada khalayak untuk berpikir apakah ada keuntungan bagi mereka mendapatkan informasi yang disampaikan.
Pemilihan media komunikasi efektif bagi persuasif harus disesuaikan dengan karakteristik isi dan tujuan isi pesan yang ingin disampaikan kepada khalayak. Berikut ini Media Komunikasi efektif yang bisa digunakan untuk menyampaikan pesan, seperti media cetak, media elektronik, media luar ruangan, media format kecil, saluran komunikasi kelompok, saluran komunikasi antar pribadi, dan internet. Sebuah proses komunikasi yang dilaksanakan tidak luput dari berbagai hambatan. Karena itu perencanaan komunikasi bertujuan untuk mengatasi hambatan agar komunikasi yang dilakukan efektif. Selain itu, perencanaa komunikasi diperlukan untuk mengimplementasikan program-program yang ingin dicapai, apakah untuk pencitraan, pemasaran, penyebarluasan gagasan, kerjasama atau pembangunan infrastruktur komunikasi. Strategi komunikasi sebagai suatu rancangan yang dibuat untuk mengubah tingkah laku manusia dalam skala yang lebih besar melalui transfer ide-ide baru. Seorang pakar perencanaan komunikasi menyatakan bahwa strategi komunikasi adalah kombinasi yang terbaik dari semua elemen komunikasi mulai dari komunikator, pesan, saluran (media), penerima sampai pada pengaruh (efek) yang dirancang untuk mencapai tujuan komunikasi yang optimal (Cangara, 2015).

Pemilihan strategi komunikasi merupakan langkah yang krusial dan memerlukan penanganan secara hati-hati dalam perencanaan komunikasi, sebab jika pemilihan strategi salah atau keliru maka hasil yang diperoleh bisa fatal dan mengakibatkan kerugian dari segi waktu, tenaga dan materi. Oleh karena itu strategi merupakan suatu rahasia yang disembunyikan oleh perencananya. Penelitian ini bertujuan untuk mengidentifikasi potensi pariwisata di Kampung Ciharegem dan mengidentifikasi media komunikasi persuasif yang ada di Tebing Keraton, Kampung Ciharagem.

\section{METODE}

Pendekatan yang digunakan dalam penelitian ini adalah pendekatan penelitian kualitatif. Pendekatan kualitatif diarahkan pada latar dan individu tersebut secara holistik (utuh). Pendekatan kualitatif di dalam penelitian ini digunakan untuk mendapatkan data yang mendalam. Untuk itu, peneliti mengumpulkan dan menganalisis datadata temuan lapangan dan menyajikannya secara deskriptif beserta makna yang dikandungnya Penelitian ini dilakukan di Kampung Ciharegem, Desa Ciburial, Kecamatan Cimenyan, Kabupaten Bandung Barat. Dipilihnya lokasi tersebut karena terdapat daya tarik wisata unggulan, yaitu Tebing Keraton, yang terletak di kawasan Sesar Lembang yang sangan berpotensi akan terjadinya bencana alam.

Pengumpulan data primer dilakukan dengan menggunakan metode observasi dan wawancara. Penentuan narasumber dan narasumber kunci yang dijadikan sumber utama dalam penelitian ini, dilakukan dengan purposive snowball sampling, yang dilakukan dari mulai tingkat pusat hingga tingkat lokal. Metode 
pengumpulan data sekunder dilakukan dengan survei data instansional, seperti berbagai perencanaan ruang dan pariwisata di berbagai tingkat daerah. Selain itu, data sekunder lainnya yang dikumpulkan berupa data-data statistik yang mendukung berbagai analisis yang dilakukan dalam penelitian ini seperti penelitian terdahulu dan dokumen kebijakan terkait. Penelitian ini menggunakan metode analisis kualitatif, analisis isi, dan dilengkap dengan metode analisis deskriptif kualitatif.

\section{HASIL DAN PEMBAHASAN}

Kampung Ciharegem berada dikawasan Desa Ciburial dengan kepemilikan luas wilayahnya mencakup dua Rukun Warga (RW), yaitu RW 09 dan RW 10 yang diketuai oleh Dede Kurnia (pada tahun 2017). Letak geografis Kampung Ciharegem berada di ujung Desa Ciburial yang merupakan kawasan desa berbukit dengan variasi kemiringan antara $0,8 \% ; 8,15 \%$ hingga $40 \%$. Kampung Ciharegem berada di $+/-1200 \mathrm{~m}$ di atas permukaan laut dengan pemandangan hamparan pepohonan, udara yang sejuk, asri dan alami. Kampung Ciharagem bersebelahan dengan kawasan konservasi Taman Hutan Raya Ir. H. Djuanda. Sebagaimana, Kampung Ciharegem pun menjadi kawasan wisata dengan sarana dan prasarana terkait education, research, sport dan tourism. Kegiatan perekonomian di Kampung Ciharegem didominasi oleh sektor pariwisata, sektor pertanian, peternakan, dan berdagang/industri kecil. Namun, masih banyaknya lahan kepemilikan di Kampung Ciharagem yang sudah dialihfungsikan, sehingga diperlukannya optimalisasi fungsi dari penggunaan lahan setempat.

Sebagian masyarakat Kampung Ciharegem sudah mampu berpikir modern dan sadar lingkungan, hal ini dapat terlihat dari suasanan kampung yang bersih, tertib dan teratur. Meskipun disisi lain, masih kurangnya pemberdayaan masyarakat yang berbentuk aktifitas di sekitar kawasan wisata Kampung Ciharegem, terutama terkait kurangnya pengetahuan warga tentang kepariwisataan. Kampung Ciharegem belum memiliki konsep pemberdayaan masyarakat dalam peningkatan kapabilitas masyarakat. Sehingga, masih sedikit masyarakat yang merasakan manfaat adanya tempat wisata di daerah Kampung Ciharegem. Oleh sebab itu, adanya usaha dari masyarakat untuk ikut berpartisipasi dengan membentuk kelompok usaha kecil menengah serta mandiri (tempat penginapan, kerajinan tangan/ souvenir).

Pemerintah telah melakukan bimbingan dan dukungan dalam bentuk penyuluhan dan forum musyawarah tentang kepariwisataan yang di bimbing oleh Disbudpar Jawa Barat, namun bimbingan dan dukungan belum dilakukan secara berkesinambungan. Namun masih minimnya kapasitas dan kapabilitas masyarakat untuk mengelola lingkungan wisata (pelayanan masih bersifat tradisional, area perdagangan belum tertata degan baik, pengelolaan lahan parkir. Tersedianya layanan dan himbauan berupa peraturan ancaman maupun risiko terjadinya bencana alam atau informasi terkait sesar lembang melalui aplikasi inarisk, namun agaknya sulit untuk diakses karena informasi yang tercantum bukan data terbaru.

Berdasarkan data pemerintah Desa Ciburial pada tahun 2015, Kampung Ciharegem Puncak memiliki potensi di beberapa sektor, yaitu di sektor pertanian, peternakan, kerajinan industri kecil, dan pariwisata. Di sektor pertanian, warga Kampung Ciharegem Puncak menghasilkan kentang, kubis, bawang merah, wortel, kemangi terong, mentimun, jahe, lengkuas, mengkudu, dan lain-lain. Berikutnya pada sektor peternakan terdapat sapi, kambing, dan madu. Selanjutnya di sektor industri kecil, terdapat makanan, anyaman, dan ukiran kayu. Kemudian pada sektor pariwisata terdapat Tebing Keraton. Tebing Keraton adalah destinasi wisata yang memiliki daya tarik berupa keindahan pemandangan pepohonan serta udara yang sejuk. Hanya saja, jalan yang mengarah ke Tebing Keraton juga memperbanyak ramburambu perlu diperhatikan lebih lanjut sehingga wisatawan semakin mudah dalam berkunjung ke sana.

Merancang suatu komunikasi untuk membangkitkan wisata di Kampung Ciharegem, Desa Ciburial dengan memilih media paling tepat, efektif, dan efisien. Ada beberapa hal yang dapat dilakukan dalam konsep perancangan komunikasi, yaitu membuat serangkaian perencanaan serta kegiatan untuk memperkenalkan wisata di Desa Ciburial kepada masyarakat melalui media promosi yang dipilih, dan juga efektif untuk menjangkau target wisatawan. Perancangan komunikasi dilakukan melaui beberapa media, yaitu: poster, x-banner, brosur, pin, kaos, baliho, print ad, billboard, transportasi, dan lain sebagainya (Lvianto et al., 2017).

Strategi komunikasi dengan menggunakan media fisik sudah dilakukan oleh pengelola kawasan pariwisata di Kampung Ciharegem dan Desa Ciburial melalu media spanduk yang dipasang di sisi jalan dengan diikat di antara batang pohon, pagar atau dengan dipaku di dinding batu. Selain sebagai media komunikasi, di sekitar area Sesar Lembang terdapat sebuah palang peringatan yang dipasang oleh badan SAR (Search and Rescue), BNPB (Badan Nasional Penanggulangan Bencana), BPBD (Badan Penanggulangan Bencana Daerah), Pemerintah Jawa Barat, dan KPUPR (Kementerian Pekerjaan Umum dan Pendudukan Rakyat) sebagai upaya pencegahan.

Di sisi lain, terdapat pemanfaatan media komunikasi daring di kawasan Sesar Lembang. Di Kampung Ciharegem tidak memiliki satu pun bentuk media sosial, hal tersebut dapat dimaklumi karena Ciharegem merupakan kampung yang besar komunitas dan pemerintahannya terlalu kecil untuk dibuat sebuah media sosial. Desa Ciburial mempunyai media sosial yang sangat aktif dengan update situs web (ciburial.desa.id) terakhir tanggal 7 Juli, serta Instagram (@desaciburial), Twitter (@desaciburial) dan Facebook (Desa Ciburial Bandung) 16 Juli. Khusus Instagram dan Facebook tampaknya antar post memiliki satu link, sebagaimana ketika hendak mengunggah sebuah foto ke 
Instagram terdapat tautan untuk membagikan ulang ke Facebook. Sedangkan di Twitter admin juga me-retweet balasan dari responden.

Kecamatan Cimenyan hanya mempunyai situs web resmi (kecamatancimenyan.bandungkab.go.id) dengan update terakhir 12 November 2019. Sedangkan bentuk media sosial Kecamatan Cimenyan lainnya rata-rata diwakili oleh desa yang dibawahinya. Selain itu peneliti harus berhati-hati dalam mengklik link media sosial milik Desa Cimenyan atau Kecamatan Cimenyan.

Meskipun saat ini penggunaan media literasi secara fisik ataupun cetak dihambat oleh pembatasan sosial berskala besar Covid-19, masih dapat membuat desain cetak berupa pamflet atau buku saku beserta spanduk. Pembuatan poster juga dapat diperhitungkan, namun akan berdampak kurang efektif karena (1) ukuran poster yang rata-rata kecil menyebabkan orang-orang akan cenderung melewatinya, (2) ukuran kecil tersebut harus mencetak lebih banyak kopi, berdampak boros; dan (3) faktor cuaca, baik kemarau atau hujan, akan merusak dan/atau memudarkan tinta pada poster. Permasalahan poster ini dapat dihindari jika Kampung Ciharegem dan Desa Ciburial memiliki sebuah mading umum, namun masih akan berisiko dilewati orang tanpa dibaca sekilas.

Media fisik dapat dibagikan kepada kantor desa dalam bentuk file .png dan .pdf. Bentuk file .png mempunyai resolusi yang lebih baik daripada .jpg, terutama jika hasil desain 'ramai' sehingga menghindari efek 'pecah' gambar yang terkompres. Sementara file .pdf lebih baik digunakan untuk pamflet dan buku saku, karena mempunyai beberapa halaman. File .pdf sangat praktis untuk disebar ke penduduk seandainya Desa Ciburial dan Kampung Ciharegem mempunyai grup pesan baik Line maupun WhatsApp. Jika perlu, buku saku dapat diupload secara online lewat situs Issuu, tentu saja dengan dikompres menjadi file .pdf dahulu.

\section{SIMPULAN}

Edukasi dan literasi kebencanaan melalui media komunikasi persuasif secara umum dapat membantu mengedukasi wisatwan. Di Desa Cigaregem, terdapat spanduk dan papan informasi sebagai media komunikasi persuasif. Selain itu, pihak Desa Ciburial dan Kecamatan Cimenyan membantu mengkomunikasikan melalui media daring seperti media sosial dan situs web. Upaya-upaya tersebut bertujuan untuk mengedukasi wisatwan yang berkunjung ke Tebing Keraton yang sangat rentan terhadap bencana alam.

\section{DAFTAR PUSTAKA}

Brown, T. J., Ham, S. H., \& Hughes, M. (2010). Picking up litter: An application of theorybased communication to influence tourist behaviour in protected areas. Journal of Sustainable Tourism, 18(7), 879-900. https://doi.org/10.1080/09669581003721281

Bungin, B. (2015). Metodologi Penelitian Kuantitatif (2nd ed.). Prenadamedia Group.

Cangara, H. (2015). Perencanaan \& $\{$ Strategi\} \{Komunikasi $\}$. PT. Rajagrafindo Persada.

Curtin, S. (2010). Managing the wildlife tourism experience: The importance of tour leaders. International Journal of Tourism Research, 12(3), 219-236. https://doi.org/10.1002/jtr.747

Gass, R. H., \& Seiter, J. S. (2015). Persuasion: Social Inflence and Compliance Gaining. Gass, R. H., \& Seiter, J. S.

Gössling, S., \& Peeters, P. (2015). Assessing tourism's global environmental impact 19002050. Journal of Sustainable Tourism, 23(5), 639-659. https://doi.org/10.1080/09669582.2015.100850 0

Hammitt, W. E., \& Cole, D. N. (1998). Wildland recreation: $\{$ Ecology\} and management (2nd ed.). John Wiley.

Hawkins, R., \& Vorster, S. (2014). Greening accommodation. In Green Growth and Travelism: Concept, Policy and Practice for Sustainable Tourism (In T. Dela, pp. 59-82). Routledge.

Luchs, M. G., Naylor, R. W., Irwin, J. R., \& Raghunathan, R. (2010). The sustainability liability: Potential negative effects of ethicality on product preference. Journal of Marketing, 74(5), 18-31. https://doi.org/10.1509/jmkg.74.5.18

Lvianto, Y. D., Bangsa, P. G., \& Christianna, A. (2017). Perancangan Media Promosi Trick Art Old City di Kota Semarang. Jurnal DKV Adiwarna, 1(10).

Manning, R. E. (2007). Parks and carrying capacity: commons without tragedy. In Choice Reviews Online (Vol. 45, Issue 01). Island Press. https://doi.org/10.5860/choice.45-0265

Melissen, F., Koens, K., Brinkman, M., \& Smit, B. (2016). Sustainable development in the accommodation sector: A social dilemma perspective. Tourism Management Perspectives, 20, 141-150. https://doi.org/10.1016/j.tmp.2016.07.008

O'Keefe, D. J. (2002). Persuasion: Theory and Research (Second Edition). In Saga Publications, Inc. (Vol. 3). Thousand Oaks, CA: Sage.

Perloff. (1993). The Dynamics of Persuasion. In The Dynamics of Persuasion (Vol. 4). Routledge. https://doi.org/10.4324/9781410606884

Teven, J. J., \& McCroskey, J. C. (1999). Goodwill: \{A\} re-examination of the construct and its measurement. Communication Monographs, 66(1), 90-103.

Warren, C., Becken, S., \& Coghlan, A. (2017). Using persuasive communication to co-create 
behavioural change-engaging with guests to save resources at tourist accommodation facilities. Journal of Sustainable Tourism, 25(7), 935-954. https://doi.org/10.1080/09669582.2016.124784 9

Wiseman, R. L., Sanders, J. A., Congalton, J. K., Gass, R. H., Sueda, K., \& Ruiqing, D. (1995). A Cross-Cultural Analysis of Compliance Gaining: China, Japan and the United State. Intercultural Communication Studies, 8(1), 118. 